\title{
Hemolytic Uremic Syndrome, CTCAE
}

National Cancer Institute

\section{Source}

National Cancer Institute. Hemolytic Uremic Syndrome, CT CAE. NCI Thesaurus. Code C143536.

A disorder characterized by a form of thrombotic microang iopathy with renal failure, hemolytic anemia, and severe thrombocytopenia. 